\title{
Factors Associated with the Change in Carotid Maximum Intima-Media Thickness in Patients with Moderate-to-Advanced Stage Chronic Kidney
}

\section{Disease}

This article was published in the following Dove Press journal:

Diabetes, Metabolic Syndrome and Obesity: Targets and Therapy

\section{Keiji Hirai (D) \\ Junki Morino \\ Saori Minato \\ Shohei Kaneko \\ Katsunori Yanai \\ Yuko Mutsuyoshi \\ Hiroki Ishii \\ Momoko Matsuyama \\ Taisuke Kitano \\ Akinori Aomatsu \\ Haruhisa Miyazawa \\ Kiyonori Ito \\ Yuichiro Ueda \\ Susumu Ookawara \\ Yoshiyuki Morishita}

Division of Nephrology, First

Department of Integrated Medicine, Saitama Medical Center, Jichi Medical University, Saitama, Japan
Correspondence: Keiji Hirai

Division of Nephrology, First Department of Integrated Medicine, Saitama Medical Center, Jichi Medical University, I-847

Amanuma-cho, Omiya-ku, Saitama-shi,

Saitama-ken 330-8503, Japan

Tel +8I-48-647-2III

Fax +8I-48-647-683 I

Email keijihirai@kfy.biglobe.ne.jp
Purpose: The objective of this study was to determine factors associated with the change in carotid maximum intima-media thickness (IMT), an established surrogate marker of atherosclerosis, in moderate-to-advanced stage chronic kidney disease (CKD) patients.

Methods: In total, 130 moderate-to-advanced stage CKD patients (mean age: $67.6 \pm 11.0$ years old; 91 men and 39 women) were included in this retrospective, single-center, observational study. Relationships between the change in carotid maximum IMT and clinical and laboratory data were analyzed by using multivariate linear regression analyses.

Results: Mean observation period was $2.9 \pm 1.6$ years. Mean carotid maximum IMT at baseline was $2.2 \pm 1.0 \mathrm{~mm}$, and the annual change in carotid maximum IMT was $0.06 \pm$ $0.22 \mathrm{~mm} /$ year. Low-density lipoprotein (LDL)-cholesterol $(\beta=0.173, \mathrm{p}<0.05)$ and annual change in triglyceride $(\beta=0.175, \mathrm{p}<0.05)$ independently correlated with the annual change in carotid maximum IMT.

Conclusion: Increases in LDL-cholesterol and triglyceride were associated with the rate of progression of carotid maximum IMT in moderate-to-advanced stage CKD patients.

Keywords: atherosclerosis, carotid maximum intima-media thickness, chronic kidney disease

\section{Introduction}

Atherosclerosis is a frequently observed complication in patients with chronic kidney disease (CKD). ${ }^{1}$ Various factors including uremic toxins, oxidative stress, diabetes mellitus, hypertension, and dyslipidemia have been considered to be responsible for progression of atherosclerosis in CKD patients. ${ }^{2}$ Atherosclerosis contributes to the development of cardiovascular diseases including coronary artery disease and stroke, which are common causes of death in CKD patients. ${ }^{3}$ Therefore, assessment of subclinical atherosclerosis is important for preventing the development and progression of cardiovascular disease. ${ }^{4}$

Carotid intima-media thickness (IMT) is an indicator of generalized atherosclerosis. ${ }^{5}$ Measurement of carotid IMT with ultrasonography is noninvasive, repeatable, and easy to perform. Compared with mean IMT, maximum IMT has been reported to more strongly predict coronary artery disease. ${ }^{6}$ Additionally, several studies have shown that the progression of carotid maximum IMT was associated with the risk of developing atherosclerotic disease, including coronary 
artery disease and stroke. ${ }^{7,8}$ Therefore, carotid maximum IMT has been widely used as a surrogate marker for atherosclerosis and cardiovascular disease. In moderate-toadvanced stage CKD patients, blood pressure and renal function have been shown to be associated with changes in mean IMT. ${ }^{9,10}$ However, few studies have examined the factors associated with progression of carotid maximum IMT in moderate-to-advanced stage CKD patients. Therefore, in the present study, we investigated the factors associated with changes in carotid maximum IMT in moderate-to-advanced stage CKD patients.

\section{Methods}

\section{Ethical Statement}

This study protocol was approved by the institutional review board of Saitama Medical Center, Jichi Medical University (RIN S20-024) and was conducted in accordance with the ethical principles contained the Declaration of Helsinki and its subsequent amendments. Written informed consent was not obtained because of the retrospective study design. The patient data were treated carefully to keep confidentiality. We presented the study information on the notice boards in our institution and informed all the patients of their opt out rights, therefore only those who chose to opt out were excluded.

\section{Patients}

We collected and analyzed the data from patients who had regularly visited Saitama Medical Center, Jichi Medical University between 2010 and 2018. Inclusion criteria were: 1) age $>20$ years; 2) estimated glomerular filtration rate (eGFR) $<60 \mathrm{~mL} / \mathrm{min} / 1.73 \mathrm{~m}^{2}$ (CKD stage $\mathrm{G} 3$ to G5); and 3) carotid artery ultrasonography performed twice with an interval of 1 year or more. The exclusion criteria were: 1) renal replacement therapy; 2) patients who wished to opt out from the study. Based on previous reports, ${ }^{9,10}$ patients with early stage CKD (G1 and G2) were excluded from the study.

\section{Study Design}

This study was a retrospective, single-center, observational study involving 130 patients. Figure 1 shows a diagram of the study design. Demographic and clinical data were obtained from patient medical charts. Factors that were independently associated with the change in carotid maximum IMT during the study period were analyzed by using multivariate linear regression analysis.

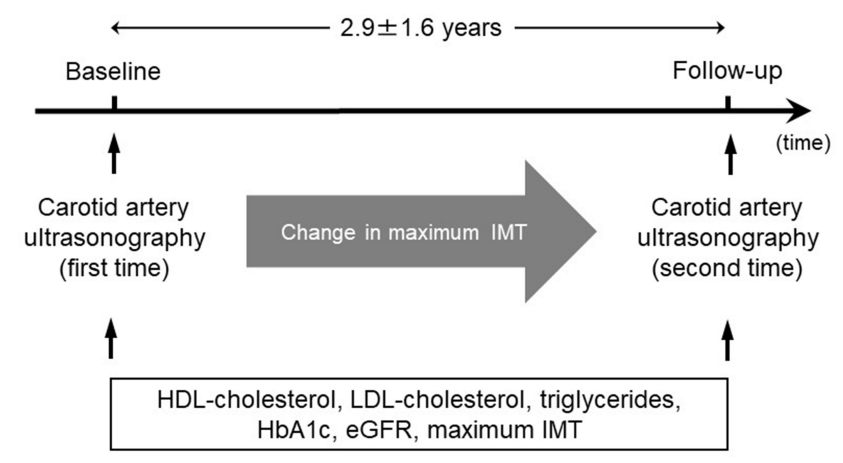

Figure I Study design.

Abbreviations: eGFR, estimated glomerular filtration rate; HbAlc, serum hemoglobin Alc; HDL, high-density lipoprotein; IMT, intima-media thickness; LDL, lowdensity lipoprotein.

\section{Laboratory methods}

Blood and urinary data were measured at the Department of Clinical Laboratory, Saitama Medical Center. Serum hemoglobin A1c (HbAlc) levels are shown as National Glycohemoglobin Standardization Program format values. eGFR was calculated by a modified equation of the Modification of Diet in Renal Disease study for Japanese patients with chronic kidney disease as follows: eGFR $\left(\mathrm{mL} / \mathrm{min} / 1.73 \mathrm{~m}^{2}\right)=194 \times(\text { serum creatinine })^{-1.094} \times$ (age $)^{-0.287} \times(0.739$ if female $) .{ }^{11}$ Hypertension was defined by an average systolic blood pressure $\geq 140 \mathrm{mmHg}$ or/and diastolic blood pressure $\geq 90 \mathrm{mmHg}$, or current use of blood pressure-lowering drugs. Diabetes mellitus was defined by $\mathrm{HbA} 1 \mathrm{c}$ level $\geq 6.5 \%$ or current use of blood glucose lowering drugs or/and insulin treatment.

\section{Ultrasonographic Measurement of Carotid Maximum IMT}

Carotid maximum IMT was determined using a B-mode ultrasound imaging with a $7.5-\mathrm{MHz}$ linear transducer (Aplio 500; Toshiba Medical Systems, Tokyo, Japan). Carotid IMT was determined as the distance between two echogenic lines corresponding to the lumen-intima interface and the media-adventitia interface on the far wall of the artery (Figure 2A) ${ }^{12}$ Carotid maximum IMT was defined as the greatest measurable carotid IMT on the left and right sides of the common carotid artery, bifurcation, and internal carotid artery (Figure 2B). All scans were carried out by experienced ultrasonographers.

\section{Statistical Analysis}

Statistical analyses were carried out using JMP 11 software (SAS Institute Inc., North Carolina, USA). Data are 


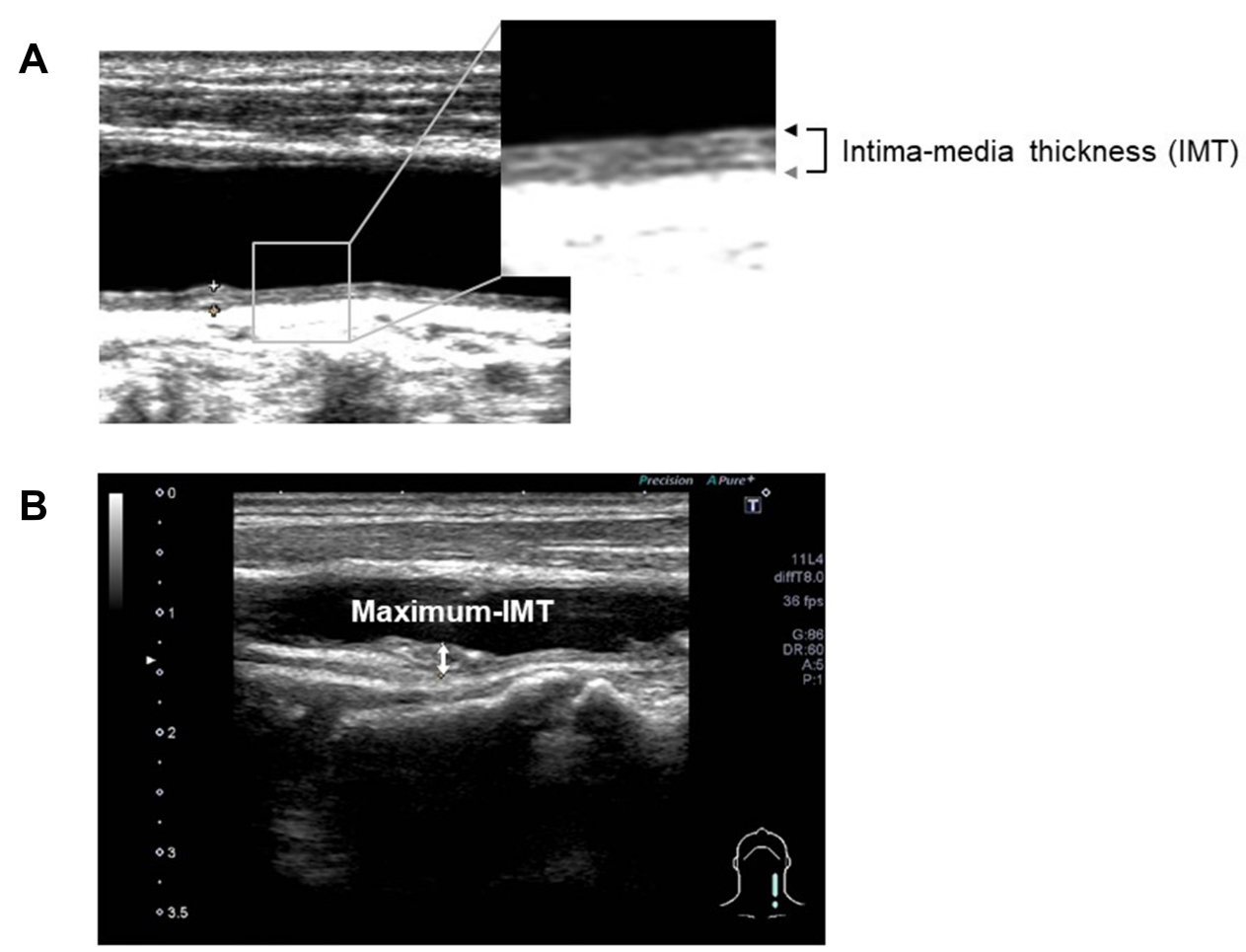

Figure 2 Longitudinal B-mode ultrasonographic images of the common carotid artery. (A) IMT was determined as the distance between the lumen-intima interface (black arrow) and the media-adventitia interface (gray arrow). (B) Maximum IMT was recorded as the largest IMT value measured on both sides of the common carotid artery, bifurcation, and internal carotid artery (two-headed arrow).

Abbreviation: IMT, intima-media thickness.

presented as means \pm standard deviations for continuous variables, and as numbers and percentages for categorical variables. Annual changes in carotid maximum IMT and lipid parameters were calculated by subtracting baseline data from follow-up data, and dividing the differences by the observation period. Correlations between two variables were examined by linear regression analyses. Multivariate linear regression analysis was performed using the stepwise forward selection method with entry criterion of $p<$ 0.05 and removal criterion of $\mathrm{p}<0.05$. P-values $<0.05$ were considered to indicate statistical significant.

\section{Results}

\section{Baseline Parameters and Medication Use}

Baseline parameters and medication use of patients are shown in Table 1. In total, 130 patients (mean age: 67.6 \pm 11.0 years old; 91 men and 39 women) were analyzed. Mean observation period was $2.9 \pm 1.6$ years. Mean eGFR at baseline was $31.3 \pm 12.6 \mathrm{~mL} / \mathrm{min} / 1.73 \mathrm{~m}^{2}$, and $\mathrm{CKD}$ stages were: stage G3a, 23 (18\%); stage G3b, 42 (32\%); stage G4, 52 (40\%); and stage G5, 13 (10\%). Mean carotid maximum IMT at baseline was $2.2 \pm 1.0 \mathrm{~mm}$ and the annual change in carotid maximum IMT was $0.06 \pm$
$0.22 \mathrm{~mm} /$ year. The distribution of patients according to annual changes in maximum IMT of the carotid artery is shown in Figure 3. The proportions of patients with diabetes mellitus, dyslipidemia, and hypertension were $38 \%$, $84 \%$, and $95 \%$, respectively. The proportions of patients with a history of coronary artery disease, ischemic stroke, and peripheral artery disease were $13 \%, 14 \%$, and $11 \%$, respectively. Medication use among patients was as follows: antiplatelet agent, 35\%; statin, 65\%; eicosapentaenoic acid, 52\%; antihypertensive drug, 89\%; reninangiotensin system blocker, 74\%; aldosterone receptor antagonist, 7\%; $\beta$-blocker, 27\%; calcium channel blocker, 69\%; diuretic, 28\%; antihyperuricemic drug, 74\%; dipeptidyl peptidase 4 inhibitor, $18 \%$; glucagon-like peptide-1 receptor agonist, 10\%; insulin, 12\%; vitamin D analogue, $18 \%$; phosphate binder, $1 \%$; and corticosteroid, $6 \%$.

\section{Factors Associated with Change in Carotid Maximum IMT}

Simple linear regression analysis showed that the annual change in carotid maximum IMT significantly correlated with change in high-density lipoprotein (HDL)-cholesterol (standard coefficient $(\beta)=-0.209, \mathrm{p}<0.05$ ), change in 
Table I Baseline Parameters and Medication Use

\begin{tabular}{|c|c|}
\hline & $\begin{array}{l}\text { All Patients }(\mathrm{n}= \\
\text { I30) }\end{array}$ \\
\hline Age (years) & $67.6 \pm 11.0$ \\
\hline Male sex (number, \%) & 91 (70\%) \\
\hline Body mass index $\left(\mathrm{kg} / \mathrm{m}^{2}\right)$ & $24.2 \pm 3.9$ \\
\hline Systolic blood pressure $(\mathrm{mmHg})$ & $137.6 \pm 18.5$ \\
\hline Diastolic blood pressure $(\mathrm{mmHg})$ & $78.8 \pm 12.1$ \\
\hline HDL-cholesterol (mg/dL) & $48.7 \pm 14.9$ \\
\hline LDL-cholesterol (mg/dL) & $96.2 \pm 29.8$ \\
\hline Triglycerides (mg/dL) & $159.6 \pm 101.3$ \\
\hline Change in HDL-cholesterol (mg/dL/year) & $-0.4 \pm 5.6$ \\
\hline Change in LDL-cholesterol (mg/dL/year) & $-6.4 \pm 15.7$ \\
\hline Change in triglyceride $(\mathrm{mg} / \mathrm{dL} /$ year $)$ & $3.1 \pm 51.6$ \\
\hline Uric acid $(\mathrm{mg} / \mathrm{dL})$ & $6.6 \pm 1.4$ \\
\hline HbAlc (\%) & $6.4 \pm 1.1$ \\
\hline Total calcium (mg/dL) & $9.1 \pm 0.5$ \\
\hline Phosphate (mg/dL) & $3.5 \pm 0.6$ \\
\hline C-reactive protein $(\mathrm{mg} / \mathrm{dL})$ & $0.13 \pm 0.17$ \\
\hline CKD stage (number, \%) & \\
\hline G3a & $23(18 \%)$ \\
\hline G3b & $42(32 \%)$ \\
\hline G4 & $52(40 \%)$ \\
\hline G5 & $13(10 \%)$ \\
\hline eGFR $\left(\mathrm{mL} / \mathrm{min} / 1.73 \mathrm{~m}^{2}\right)$ & $31.3 \pm 12.6$ \\
\hline Change in eGFR $\left(\mathrm{mL} / \mathrm{min} / 1.73 \mathrm{~m}^{2} /\right.$ year $)$ & $-2.1 \pm 3.1$ \\
\hline Urinary protein excretion $(\mathrm{g} / \mathrm{gCr})$ & $1.4 \pm 2.0$ \\
\hline Maximum IMT of the carotid artery $(\mathrm{mm})$ & $2.2 \pm 1.0$ \\
\hline $\begin{array}{l}\text { Change in maximum IMT of the carotid artery } \\
(\mathrm{mm} / \text { year) }\end{array}$ & $0.06 \pm 0.22$ \\
\hline Observation period (years) & $2.9 \pm 1.6$ \\
\hline Underlying causes of CKD (number, \%) & \\
\hline Hypertensive nephrosclerosis & 49 (37.7\%) \\
\hline Diabetic kidney disease & $44(33.8 \%)$ \\
\hline Chronic glomerulonephritis & 25 (19.2\%) \\
\hline Chronic interstitial nephritis & $3(2.3 \%)$ \\
\hline Polycystic kidney disease & $4(3.1 \%)$ \\
\hline Obstructive nephropathy & $2(1.5 \%)$ \\
\hline Vasculitis & $3(2.3 \%)$ \\
\hline Hypertension (number, \%) & $123(95 \%)$ \\
\hline Hyperuricemia (number, \%) & $116(89 \%)$ \\
\hline Dyslipidemia (number, \%) & $109(84 \%)$ \\
\hline Diabetes mellitus (number, \%) & $49(38 \%)$ \\
\hline Coronary artery disease (number, \%) & $17(13 \%)$ \\
\hline Ischemic stroke (number, \%) & $18(14 \%)$ \\
\hline Peripheral artery disease (number, \%) & 14 (11\%) \\
\hline Past or current smoking (number, \%) & $75(58 \%)$ \\
\hline Antiplatelet agent (number, \%) & $45(35 \%)$ \\
\hline Statin (number, \%) & $84(65 \%)$ \\
\hline Eicosapentaenoic acid (number, \%) & $67(52 \%)$ \\
\hline Antihypertensive drug (number, \%) & 116 (89\%) \\
\hline Renin-angiotensin system blocker (number, \%) & $96(74 \%)$ \\
\hline
\end{tabular}

(Continued)
Table I (Continued).

\begin{tabular}{|l|l|}
\hline & $\begin{array}{l}\text { All Patients (n = } \\
\text { I30) }\end{array}$ \\
\hline Aldosterone receptor antagonist (number, \%) & $9(7 \%)$ \\
$\beta$-blocker (number, \%) & $35(27 \%)$ \\
Calcium channel blocker (number, \%) & $90(69 \%)$ \\
Diuretic (number, \%) & $37(28 \%)$ \\
Antihyperuricemic drug (number, \%) & $96(74 \%)$ \\
Dipeptidyl peptidase 4 inhibitor (number, \%) & $24(18 \%)$ \\
Glucagon-like peptide-I receptor agonist & $13(10 \%)$ \\
(number, \%) & $15(12 \%)$ \\
Insulin (number, \%) & $23(18 \%)$ \\
Vitamin D analogue (number, \%) & $1(1 \%)$ \\
Phosphate binder (number, \%) & $8(6 \%)$ \\
Corticosteroid (number, \%) & 9 \\
\hline
\end{tabular}

Abbreviations: CKD, chronic kidney disease; eGFR, estimated glomerular filtration rate; HbAlc, serum hemoglobin Alc; HDL, high-density lipoprotein; IMT, intima-media thickness; LDL, low-density lipoprotein.

triglyceride $(\beta=0.173, \mathrm{p}<0.05)$, eGFR $(\beta=0.182, \mathrm{p}<$ $0.05)$, and maximum IMT of the carotid artery $(\beta=$ $-0.201, \mathrm{p}<0.05)$ (Table 2). Multivariate stepwise linear regression analysis revealed that low-density lipoprotein (LDL)-cholesterol $(\beta=0.173, p<0.05)$ and annual change in triglyceride $(\beta=0.175, \mathrm{p}<0.05)$ independently correlated with the annual change in carotid maximum IMT.

\section{Discussion}

In the present study, we investigated the factors associated with changes in carotid maximum IMT in moderate-toadvanced stage CKD patients. We found that baseline LDL-cholesterol concentration and annual change in triglyceride concentration were associated with the annual

Annual change in maximum IMT of the carotid artery

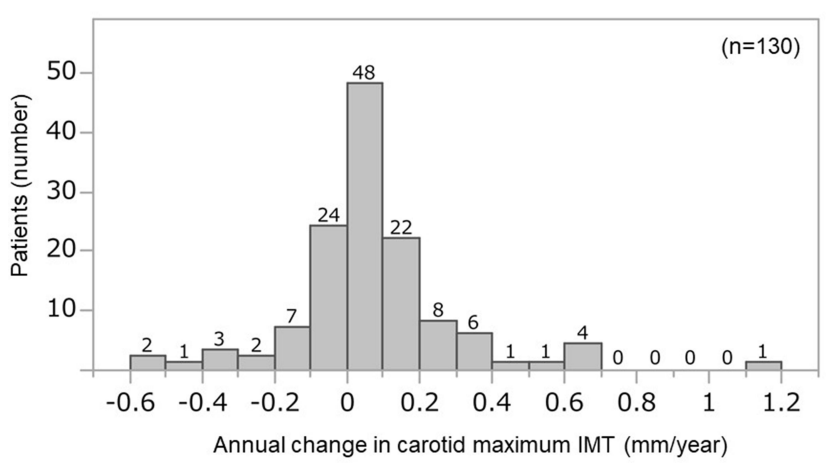

Figure 3 Distribution of patients according to annual change in maximum IMT of the carotid artery.

Abbreviation: IMT, intima-media thickness. 
Table 2 Simple and Multivariate Linear Regression Analyses of Variables Associated with the Annual Change in Carotid Maximum IMT During the Observation Period

\begin{tabular}{|c|c|c|c|c|}
\hline \multirow[t]{2}{*}{ Variable } & \multicolumn{2}{|c|}{ Simple Linear Regression Analysis } & \multicolumn{2}{|c|}{ Multivariate Linear Regression Analysis } \\
\hline & Standard Coefficient & P-value & Standard Coefficient & P-value \\
\hline Age (years) & 0.007 & 0.93 & & \\
\hline Male sex (yes vs no) & -0.044 & 0.62 & & \\
\hline Body mass index $\left(\mathrm{kg} / \mathrm{m}^{2}\right)$ & -0.039 & 0.66 & & \\
\hline Systolic blood pressure $(\mathrm{mmHg})$ & 0.027 & 0.76 & & \\
\hline HDL-cholesterol (mg/dL) & 0.016 & 0.86 & & \\
\hline LDL-cholesterol (mg/dL) & 0.172 & 0.05 & 0.173 & $<0.05$ \\
\hline Triglycerides (mg/dL) & 0.106 & 0.23 & & \\
\hline Change in HDL-cholesterol (mg/dL/year) & -0.209 & $<0.05$ & & \\
\hline Change in LDL-cholesterol (mg/dL/year) & -0.123 & 0.16 & & \\
\hline Change in triglyceride (mg/dL/year) & 0.173 & $<0.05$ & 0.175 & $<0.05$ \\
\hline $\mathrm{HbAlc}(\%)$ & -0.149 & 0.22 & & \\
\hline Total calcium (mg/dL) & 0.129 & 0.15 & & \\
\hline Phosphate (mg/dL) & -0.042 & 0.64 & & \\
\hline C-reactive protein $(\mathrm{mg} / \mathrm{dL})$ & -0.077 & 0.38 & & \\
\hline eGFR $\left(\mathrm{mL} / \mathrm{min} / 1.73 \mathrm{~m}^{2}\right)$ & 0.182 & $<0.05$ & & \\
\hline Change in eGFR $\left(\mathrm{mL} / \mathrm{min} / 1.73 \mathrm{~m}^{2} /\right.$ year $)$ & 0.001 & 0.99 & & \\
\hline Maximum IMT of the carotid artery $(\mathrm{mm})$ & -0.201 & $<0.05$ & & \\
\hline Hypertension (yes vs no) & 0.018 & 0.83 & & \\
\hline Diabetes mellitus (yes vs no) & 0.112 & 0.20 & & \\
\hline Past or current smoking (yes vs no) & -0.070 & 0.43 & & \\
\hline Statin (yes vs no) & -0.070 & 0.43 & & \\
\hline Eicosapentaenoic acid (yes vs no) & 0.042 & 0.63 & & \\
\hline Antihypertensive drug (yes vs no) & -0.087 & 0.32 & & \\
\hline Incretin agent (yes vs no) & 0.105 & 0.23 & & \\
\hline
\end{tabular}

Abbreviations: eGFR, estimated glomerular filtration rate; HbAIc, serum hemoglobin AIc; HDL, high-density lipoprotein; IMT, intima-media thickness; LDL, low-density lipoprotein.

change in carotid maximum IMT in moderate-to-advanced stage CKD patients.

Carotid IMT is a well-established surrogate marker for atherosclerosis ${ }^{5}$ and is associated with various atherosclerotic risk factors such as diabetes mellitus, hypertension, and dyslipidemia. ${ }^{13}$ Several recent studies investigated factors associated with the change in carotid maximum IMT in patients without renal impairment. ${ }^{14,15}$ These studies showed that age, smoking, systolic blood pressure, and LDL-cholesterol were associated with the annual change in carotid maximum IMT. ${ }^{14,15}$ In the present study, baseline LDL-cholesterol concentration and the annual change in triglyceride concentration correlated with the annual rate of change of carotid maximum IMT.

Atherosclerosis is a chronic vascular inflammatory disease characterized by deposition of lipids and accumulation of inflammatory cells within the inner walls of arteries. ${ }^{16}$ Injury to the vascular endothelium through multivariate mechanisms including high blood pressure, hyperglycemia, and dyslipidemia leads to infiltration and retention of monocytes in the subendothelial space. ${ }^{16}$ Several studies reported that LDL-cholesterol was positively correlated with the annual change in carotid maximum IMT in patients without renal impairment. ${ }^{14,15}$ In the present study, LDL-cholesterol was positively correlated with the annual change in carotid maximum IMT in moderate-to-advanced stage CKD patients. These results suggest that LDL-cholesterol may be associated with progression of carotid atherosclerosis in both patients with and without renal impairment.

Hypertriglyceridemia is a frequently observed lipid abnormality in patients with $\mathrm{CKD}{ }^{17}$ In patients with CKD, insulin sensitivity decreases as GFR declines. ${ }^{18}$ Insulin resistance promotes hepatic production of triglyceride-rich lipoproteins such as very low-density lipoprotein, leading to development of hypertriglyceridemia. ${ }^{19}$ Additionally, the downregulation of very low-density lipoprotein receptor expression in skeletal muscle has been 
reported in an animal model of $\mathrm{CKD} .{ }^{20}$ In the present study, triglyceride was positively correlated with the annual change in carotid maximum IMT in moderate-toadvanced stage CKD patients. However, previous studies reported that triglyceride was not correlated with the annual change in carotid maximum IMT in patients without renal impairment. ${ }^{14,15}$ These results suggest that triglyceride might be associated with progression of carotid atherosclerosis in patients with renal impairment but not in patients without renal impairment.

Previous studies reported that age, smoking, and systolic blood pressure were associated with the annual change in carotid maximum IMT. ${ }^{14,15}$ In the present study, there was no association between age, smoking, blood pressure, and the annual rate of change of carotid maximum IMT. The mean age of participants was higher in this study $(67.6$ years) than in previous ones (56.3 years and 36.6 years), ${ }^{14,15}$ which may have affected our results. In the present study, almost all patients $(95 \%)$ had a history of hypertension. It has been reported that the higher range of systolic blood pressure was associated with a greater progression of carotid IMT in patients with renal impairment. ${ }^{9}$ In the present study, nearly $90 \%$ of all patients were taking antihypertensive drugs including renin-angiotensin system blocker, calcium channel blocker, and diuretic. Systolic blood pressure was controlled below $140 \mathrm{mmHg}$, which was better than that in previous study. ${ }^{14}$ These findings might explain the discrepancy between our result and those of previously published reports. A prospective cohort study of moderate-to-advanced stage CKD patients reported that neither smoking nor blood pressure was associated with progression of carotid plaque. ${ }^{21}$ Smoking and blood pressure may not be associated with progression of carotid atherosclerosis in moderate-to-advanced stage CKD patients. Further studies are necessary to clarify the factors associated with progression of carotid atherosclerosis in moderate-to-advanced stage CKD patients.

To our knowledge, this is the first study to demonstrate factors associated with changes in carotid maximum IMT in moderate-to-advanced stage CKD patients. Our results may promote further studies investigating factors associated with carotid atherosclerosis in moderate-toadvanced stage CKD patients.

This study had several limitations. First, this was a retrospective study that may have included reporting and patient's selection biases. Second, the sample size was relatively small and the study was conducted at a single center, which restricts to generalize our study findings. Third, observation periods differed among patients, which may have affected the results. Fourth, the ratio of male patients was higher than that of female patients in this study, which might have influenced the results of the study. Therefore, further large-scale, prospective, multicenter studies are required to clarify the factors associated with changes in carotid maximum IMT in moderate-to-advanced stage CKD patients.

In conclusion, increases in LDL-cholesterol and triglyceride were associated with the rate of progression of carotid maximum IMT in moderate-to-advanced stage CKD patients.

\section{Acknowledgments}

We thank Richard Robins, PhD, from Edanz Group (https://en-author-services.edanzgroup.com/) for editing a draft of this manuscript.

\section{Disclosure}

The authors declare that they have no conflicts of interest related to this manuscript.

\section{References}

1. Bello AK, Alrukhaimi M, Ashuntantang GE, et al. Complications of chronic kidney disease: current state, knowledge gaps, and strategy for action. Kidney Int Suppl (2011). 2017;7(2):122-129. doi:10.1016/j. kisu.2017.07.007

2. Valdivielso JM, Rodriguez-Puyol D, Pascual J, et al. Atherosclerosis in chronic kidney disease: more, less, or just different? Arterioscler Thromb Vasc Biol. 2019;39(10):1938-1966. doi:10.1161/ ATVBAHA.119.312705

3. Gansevoort RT, Correa-Rotter R, Hemmelgarn BR, et al. Chronic kidney disease and cardiovascular risk: epidemiology, mechanisms, and prevention. Lancet. 2013;382(9889):339-352. doi:10.1016/ S0140-6736(13)60595-4

4. Ahmadi A, Argulian E, Leipsic J, Newby DE, Narula J. From subclinical atherosclerosis to plaque progression and acute coronary events: JACC state-of-the-art review. J Am Coll Cardiol. 2019;74 (12):1608-1617. doi:10.1016/j.jacc.2019.08.012

5. O'Leary DH, Bots ML. Imaging of atherosclerosis: carotid intima-media thickness. Eur Heart J. 2010;31(14):1682-1689. doi:10.1093/eurheartj/ehq185

6. Irie Y, Katakami N, Kaneto H, et al. Maximum carotid intima-media thickness improves the prediction ability of coronary artery stenosis in type 2 diabetic patients without history of coronary artery disease. Atherosclerosis. 2012;221(2):438-444. doi:10.1016/j.atherosclerosis. 2012.01.022

7. Hirano M, Nakamura T, Kitta Y, et al. Short-term progression of maximum intima-media thickness of carotid plaque is associated with future coronary events in patients with coronary artery disease. Atherosclerosis. 2011;215(2):507-512. doi:10.1016/j.atherosclerosis. 2011.01.014

8. Kokubo Y, Watanabe M, Higashiyama A, Nakao YM, Nakamura F, Miyamoto Y. Impact of intima-media thickness progression in the common carotid arteries on the risk of incident cardiovascular disease in the suita study. J Am Heart Assoc. 2018;7(11):11. doi:10.1161/ JAHA. 117.007720 
9. Kendrick J, Chonchol M, Gnahn H, Sander D. Higher systolic blood pressure is associated with progression of carotid intima-media thickness in patients with chronic kidney disease. Kidney Int. 2010;77 (9):794-800. doi:10.1038/ki.2009.557

10. Desbien AM, Chonchol M, Gnahn H, Sander D. Kidney function and progression of carotid intima-media thickness in a community study. Am J Kidney Dis. 2008;51(4):584-593. doi:10.1053/j.ajkd.2007. 11.026

11. Matsuo S, Imai E, Horio M, et al. Revised equations for estimated GFR from serum creatinine in Japan. Am J Kidney Dis. 2009;53 (6):982-992. doi:10.1053/j.ajkd.2008.12.034

12. Pignoli P, Tremoli E, Poli A, Oreste P, Paoletti R. Intimal plus medial thickness of the arterial wall: a direct measurement with ultrasound imaging. Circulation. 1986;74(6):1399-1406. doi:10.11 61/01.CIR.74.6.1399

13. $\mathrm{Qu} \mathrm{B}, \mathrm{Qu}$ T. Causes of changes in carotid intima-media thickness: a literature review. Cardiovasc Ultrasound. 2015;13(1):46. doi:10.1186/s12947-015-0041-4

14. Rosvall M, Persson M, Ostling G, et al. Risk factors for the progression of carotid intima-media thickness over a 16-year follow-up period: the malmo diet and cancer study. Atherosclerosis. 2015;239 (2):615-621. doi:10.1016/j.atherosclerosis.2015.01.030
15. Toprak A, Kandavar R, Toprak D, et al. C-reactive protein is an independent predictor for carotid artery intima-media thickness progression in asymptomatic younger adults (from the Bogalusa Heart Study). BMC Cardiovasc Disord. 2011;11(1):78. doi:10.1186/1471-2261-11-78

16. Ross R. Atherosclerosis-an inflammatory disease. $N$ Engl J Med. 1999;340(2):115-126.

17. Mikolasevic I, Zutelija M, Mavrinac V, Orlic L. Dyslipidemia in patients with chronic kidney disease: etiology and management. Int J Nephrol Renovasc Dis. 2017;10:35-45. doi:10.2147/IJNRD.S101808

18. Kobayashi S, Maesato K, Moriya H, Ohtake T, Ikeda T. Insulin resistance in patients with chronic kidney disease. Am J Kidney Dis. 2005;45(2):275-280. doi:10.1053/j.ajkd.2004.09.034

19. Ai M, Tanaka A, Ogita K, et al. Relationship between hyperinsulinemia and remnant lipoprotein concentrations in patients with impaired glucose tolerance. J Clin Endocrinol Metab. 2000;85 (10):3557-3560. doi:10.1210/jcem.85.10.6894

20. Vaziri ND, Liang K. Down-regulation of VLDL receptor expression in chronic experimental renal failure. Kidney Int. 1997;51(3):913-919.

21. Rigatto C, Levin A, House AA, Barrett B, Carlisle E, Fine A. Atheroma progression in chronic kidney disease. Clin J Am Soc Nephrol. 2009;4(2):291-298. doi:10.2215/CJN.01840408

\section{Publish your work in this journal}

Diabetes, Metabolic Syndrome and Obesity: Targets and Therapy is an international, peer-reviewed open-access journal committed to the rapid publication of the latest laboratory and clinical findings in the fields of diabetes, metabolic syndrome and obesity research. Original research, review, case reports, hypothesis formation, expert opinion and commentaries are all considered for publication. The manuscript management system is completely online and includes a very quick and fair peer-review system, which is all easy to use. Visit http://www.dovepress.com/testimonials.php to read real quotes from published authors. 